\title{
A verbivocovisualidade criptografada de Augusto de Campos
}

\section{The encrypted verbivocovisuality of Augusto de Campos}

\author{
Luciane de Paula \\ Universidade Estadual Paulista, Assis, São Paulo, Brasil \\ Rafaela dos Santos Batista \\ Universidade Estadual Paulista, Assis, São Paulo, Brasil
}

\begin{abstract}
Resumo: Este artigo reflete sobre a poética de Augusto de Campos. Para isso, pauta-se na concepção estética empregada por ele e demais concretistas como projeto da poesia concreta: a verbivocovisualidade. O objetivo é relacionar tal percepção com a filosofia da linguagem bakhtiniana no que tange à noção de linguagem, entendida como tridimensional. A hipótese é a de que o entendimento autoral do grupo Noigandres e o do Círculo russo convergem, cada qual com sua peculiaridade, quanto à perspectiva de linguagem. A pertinência desta reflexão se encontra no avanço teórico no campo bakhtiniano. A metodologia empregada é a dialético-dialógica. Os conceitos de linguagem, enunciado, dialogia, sujeito, ideologia e vozes sociais fundamentam a discussão. A relevância se volta ao estudo contemporâneo da linguagem. Os resultados revelam a produtividade da proposta filosófica bakhtiniana na contemporaneidade, especialmente à perspectiva verbivocovisual da linguagem (concreta).
\end{abstract}

Palavras-chave: Poesia Concreta; Círculo de Bakhtin; Filosofia da Linguagem

\begin{abstract}
This article reflects on Augusto de Campos' poetics. For this, it is guided by the aesthetic conception employed by him and other concretists as a project of concrete poetry: verbivocovisuality. The objective is to relate this perception with the Bakhtinian philosophy of the language regarding the notion of language, understood as three-dimensional. The hypothesis is that the authorial understanding of the Noigandres group and that of the Russian Circle converge, each with them own peculiarity, with respect to the language perspective. The significance of this reflection is found in the theoretical advance in the Bakhtinian field. The methodology used is dialectic-dialogical. The concepts of language, enunciation, dialogue, subject, ideology and social voices underlie the discussion. The relevance turns to the contemporary study of language. The results reveal the productivity of the Bakhtinian philosophical proposal in contemporaneity, especially about a verbivocovisual perspective to (concrete) language.
\end{abstract}

Keywords: Concrete Poetry; Bakhtin Circle; Philosophy of the language

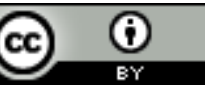




\section{Introdução}

A poesia concreta marca, no esteio de Mallarmé, um manejo elaborado com arranjo plural e não usual de linguagem. O trabalho com o verbal se estende ao visual e ao vocal/sonoro numa perspectiva poética ancorada na vida, constitutiva do homem. Em 1950, Augusto de Campos (AC), Haroldo de Campos (HC) e Décio Pignatari (DP), fundadores do grupo Noigandres, renovam a concepção de poesia ao usarem, de empréstimo, o termo verbivocovisual(idade), cunhado por Joyce, em Finnegans Wake, para nomear a própria visão de composição de linguagem poética. Essa noção marca a produção dos concretistas, integradora das dimensões verbal, vocal/sonora e visual. A língua(gem) é tratada como palavra-coisa em uso. Mais que representação do objeto no mundo, a linguagem-objeto é compreendida como a própria vida e o próprio homem. A linguagem primitiva se explicita na estrutura metalinguística das obras. Ou, como afirma Arnaldo Antunes (AA):

\footnotetext{
A origem da poesia se confunde com a origem da própria linguagem.

[...] a integridade entre nome e coisa

[...] antes que a representação rompesse seu cordão umbilical, gerando essas duas metades - significante e significado.

[...] Quando o nome da coisa era algo que fazia parte dela, assim como sua cor, seu tamanho, seu peso [...] Quando os laços entre os sentidos ainda não se haviam desfeito, então música, poesia, pensamento, dança, imagem, cheiro, sabor, consistência se conjugavam em experiências integrais, associadas a utilidades práticas, mágicas, curativas, religiosas, sexuais, guerreiras [...] [...] o ser das coisas ditas se manifestaria nelas próprias (substantivos), não numa partícula verbal externa a elas

[...] como se a fala não estivesse se referindo àquelas coisas, e sim apresentando-as (ao mesmo tempo em que se apresenta).
}

Sustentada pelo Círculo de Bakhtin, essa concepção de (língua)gem se realiza nas mudanças sociais (VOLÓCHINOV, 2017). Capaz de refletir e refratar a realidade, sujeito, vida e arte se (trans)formam e dialogam na/pela linguagem. A filosofia bakhtiniana não deixou de pensar em outras manifestações de linguagem, como a música [estudada por Volóchinov (2019) e Yudina], o teatro [assumido, junto com a literatura, por Medviédev (2012) e Bakhtin (2011; 2015)], a ópera (como a aborda Sollertinsky), as variedades linguísticas (como o faz Volóchinov) e a linguagem cotidiana [tal qual a compreende Jakubinskij (2015)]. 
A literatura (romance e poesia), o teatro, a música e a pintura, influenciados pelas vanguardas, desenvolveram uma ideia que se encontra na proposta do Círculo, a de que "[...] é indiscutível a potencial linguagem das linguagens" (BAKHTIN, 2011, p. 311) e que "O problema da totalidade construtiva tridimensional, o tempo todo, foi substituído pela questão superficial da composição como distribuição das massas verbais e dos temas verbais, e, às vezes, simplesmente como massas verbais transmentais”. (MEDVIÉDEV, 2012, p. 95).

Com vistas à proposta integral do Círculo, Paula (2017), Paula \& Serni (2017) e Paula \& Luciano (2020a, 2020b, 2020c, 2020d, 2021) percebem que o seu projeto de linguagem pode ser entendido como verbivocovisual, ainda que o termo não seja utilizado pelos pensadores.

A fundamentação teórica e o método bakhtiniano amparam a nossa discussão, junto com estudos sobre poesia concreta. Analisamos o clip-poema "Criptocardiograma" (2003), em cotejo com "Código" e "Lygia Fingers", todos de AC, como exemplo verbivocovisual interativo, tomado como empreendimento poético concreto tridimensional.

Os critérios de escolha para o objeto principal da análise ser "Criptocardiograma" foram a interação e a metalinguagem explícitas em sua tridimensionalidade. Não que isso não ocorra em outros poemas, mas são traços estilísticos de $\mathrm{AC}$ essenciais.

O nosso intuito é refletir sobre como a tridimensionalidade da linguagem se configura em interação nos poemas, uma vez que a verbivocovisualidade marca a unidade integral da poesia concreta. O verbal deixa de ser a única dimensão de sistematização poética e o papel deixa de ser o único suporte. A concretização poética ganha outras esferas e materializações. A poesia concreta tenta, como afirmou AA, recuperar a gênese da linguagem, anterior à decodificação que aparta o signo de sua pulsação. Toda essa proposta se encontra na composição estilística de $\mathrm{AC}$ como vértice icônica da poesia concreta e exemplar da concepção de trabalho ético e estético de linguagem.

Para estruturar nossa discussão, abordamos a noção de linguagem bakhtiniana, a de poesia concreta, adentramos o universo de AC, com as análises dos poemas para, por fim, chegarmos aos resultados, que apontam para a produtividade da noção de verbivocovisualidade e da interação entre os projetos bakhtiniano e concreto. 


\section{A proposta tridimensional de linguagem do Círculo de Bakhtin}

A perspectiva bakhtiniana de linguagem se centra na noção de enunciado, entendido como elo e singularidade (VOLÓCHINOV, 2013). De acordo com Volóchinov, "Na palavra se realizam os inúmeros fios ideológicos que penetram todas as áreas da comunicação social” (2017, p. 106). Palavra que é linguagem ${ }^{1}$ e esta, ideológica, o “[...] indicador mais sensível das mudanças sociais, sendo que isso ocorre lá onde essas mudanças ainda estão se formando, onde elas ainda não se constituíram em sistemas ideológicos organizados" (2017, p. 106).

A noção dialógica, eixo central da proposta bakhtiniana, calca-se na relação alteritária dos sujeitos (eu/outro) e na valoração em embate vivo: as ideologias são expressas e tomadas como realidade do ato ético e responsável, uma vez que "[...] toda palavra é um pequeno palco em que as ênfases sociais multidirecionadas se confrontam e entram em embate. Uma palavra nos lábios de um único indivíduo é um produto da interação viva das forças sociais" (VOLÓCHINOV, 2017, p. 140). Cada enunciado é impregnado de vozes sociais em luta que, a depender da configuração, coloca em movimento novos e velhos valores.

Tanto enunciado quanto gênero discursivo se caracterizam, conforme Bakhtin (2016), Medviédev (2012) e Volóchinov (2017), pela organização arquitetônica do autorcriador (BAKHTIN, 2011) do conteúdo temático, da forma composicional e do estilo, autoral e genérico, engendrados como unidade integral, a partir de um tom axiológico e emotivo-volitivo.

Essa noção de diálogo não se circunscreve apenas à dimensão verbal, mas à linguagem de maneira tridimensional, uma vez que "Qualquer fenômeno ideológico sígnico é dado em algum material: no som, na massa física, na cor, no movimento do corpo e assim por diante" (VOLÓCHINOV, 2017, p. 94). As dimensões materializam a linguagem, cada qual com seu sistema, em diálogo, ao pensarmos, como o Círculo e como os concretistas, numa proto-linguagem, que abarca todos os códigos e que, de maneira potencial ou expressiva, encontra-se, em maior ou menor grau, expressa nos enunciados. No caso da poesia concreta, com ênfase.

\footnotetext{
${ }^{1}$ Volóchinov afirma que a linguagem "É o produto da atividade humana coletiva e reflete em todos os seus elementos tanto a organização econômica como a sociopolítica da sociedade que a gerou” (2013, p. 141).
} 
O verbal não é apenas verbal, mas verbivocovisual. Os poemas canalizam essa concepção e exploram as dimensões em integração. Nesse sentido, a pertinência teórica da perspectiva dialógica bakhtiniana não apenas se apresenta interdisciplinar, como também se casa com a concepção expressa como projeto poético do grupo Noigandres. Afinal, "O enunciado verbivocovisual é considerado, em sua potencialidade valorativa, [...]" (PAULA; SERNI, 2017, p. 179-180), independente do gênero no qual se materializa.

$\mathrm{Na}$ filosofia da linguagem bakhtiniana, a percepção de uma linguagem englobante das dimensões sistêmicas verbal, visual e sonora surge, estabelecida pós reuniões do Círculo (entre 1959-1961), como a égide do pensamento do Círculo, sintetizada em:

Todo sistema de signos (isto é, qualquer língua), por mais que sua convenção se apoie em uma coletividade estreita, em princípio sempre pode ser codificada, isto é, traduzido para outros sistemas de signos (outras linguagens); consequentemente, existe uma lógica geral dos sistemas de signos, uma potencial linguagem das linguagens única (que, evidentemente, nunca pode vir a ser uma linguagem única concreta, uma das linguagens). (BAKHTIN, 2011, p. 311)

A materialização do enunciado coloca essa linguagem geral na dependência das especificidades da esfera de comunicação de produção e circulação do enunciado concreto. Essa(s) esfera(s) possui(em) regras e objetivos específicos que engendram os gêneros, nos quais se configuram os enunciados. A linguagem verbivocovisual se encontra nas marcas enunciativas explicitadas e também se manifesta nos signos interiores, na consciência cognoscível que, na compreensão ativa, apoiam-se em marcas enunciativas. A significação nasce na/da relação interior e exterior e revela a verbivocovisualidade como base que recobre enunciados desde a sua formulação até a construção de sentidos em interação.

Essa proposta repensa a concepção filosófica de linguagem no campo bakhtiniano e acarreta novas possibilidades de análises discursivas, calcadas em materialidades distintas, como enunciados visuais, musicais, sincréticos e multimodais.

A poesia concreta é composta pelo material disponível, explora a potencialidade verbivocovisual e transforma a palavra-coisa em metalinguagem viva dessa concepção: a linguagem é entendida e tomada como objeto dinâmico, concretizada no poema que, de maneira tridimensional, a mobiliza. Linguagem verbivocovisual.

Revista da Anpoll, Florianópolis, v. 52, n. 3, p. 55-75, set.-dez., 2021 | 59 
Nesses trabalhos da linguagem pela linguagem, a palavra se torna viva, fala de si e por si. A análise aqui empreendida exemplifica essa verbivocovisualidade poética e bakhtiniana. Os poemas de AC mostram como a palavra é vida e como homem e mundo a constituem. Em outras palavras, na análise poética, a ponte teórico-analítica liga as noções aqui mobilizadas.

\section{A poética concreta: tridimensionalidade verbivocovisual em ato}

A tradição poética canônica recebeu, ao longo do tempo, inovações que não agradaram a todos. Desde Baudelaire, que concedeu à realidade o direito de participar da poesia; e Mallarmé, com o primeiro poema-estrutura de superação do verso e simultaneísmo; a arte poética se mostra reveladora. A poesia concreta, com auge entre 1950-1960, nasce de um aspecto de mudança e influencia a linguagem, tanto em outros âmbitos (como na publicidade, por exemplo) quanto nas artes (como é o caso do projeto estético de AA, entre outros).

Como um dos poetas que idealizaram e colocaram tal projeto estético em funcionamento, AC trata de temas variados (angustiantes, amorosos, silenciosos, recusantes e afastados em sua poesia), com objetividade enigmática, complexidade linguística e interface com outras áreas (comunicação, design, artes plásticas e música), que não pertencem às convenções e não são totalmente compreendidas ou mesmo aceitas como poesia ou arte.

Na Exposição Nacional de Arte Concreta, no Museu de Arte Moderna (MAM) de São Paulo, em 1956, DP, HC e AC transformam a concepção de poesia com a proposta concretista ao situarem a palavra com personalidade, sem que a forma se mantenha presa em convenções que não permitam renovações de conteúdo. Segundo Pignatari et ali,

\footnotetext{
- a poesia concreta começa por assumir uma responsabilidade total perante a linguagem: aceitando o pressuposto do idioma histórico como núcleo indispensável de comunicação, recusa-se a absorver as palavras com meros veículos indiferentes, sem vida sem personalidade sem história - túmulos-tabus com que a convenção insiste em sepultar a idéia.

- o poeta concreto não volta a face às palavras, não lhes lança olhares oblíquos: vai direto ao seu centro, para viver e vivificar a sua facticidade. (1975, p. 44)
} 
No âmbito criativo concreto, o que movimenta a produção é a verbivocovisualidade, que desafia a compreensão do leitor. Este, exercita outros tipos de leitura, participativa e, de certa forma, do jogo criativo poético, que delineia a relação alteritária (eu-outro), de acordo com a filosofia bakhtiniana de construção de sentido, pois é a partir do outro que nos definimos.

A compreensão do enunciado verbivocovisual pode causar impressão de estranhamento, mas é o que marca a novidade concreta. O leitor precisa "adentrar" no poema (como em "Código"), em busca de sentidos, como um outro autor, em interação (feita por um autor-criador deslocado de sua pessoa, para dialogar com o leitor potencial do poema, como um auditório previsto, numa leitura guiada pela linguagem poética, que gera sentido e é preenchida de sentido pelo leitor, que o completa com sua voz, o que promove embate com a voz do poeta e outras vozes responsivas que no enunciado repercutem).

Como filosofia de criação, os três expoentes fundadores do movimento concreto consideram a verbivocovisualidade, sem privilegiar nenhuma das dimensões da língua(gem) e o poema é a unidade integradora enunciativa dessa vanguarda. Ao construir o sentido pela forma, de maneira situada (espaço-temporal - historicamente) com o conteúdo, a poesia acontece como ato e evento único (BAKHTIN, 2010).

Essa vanguarda desperta reações porque quebra com a tradição da poesia versificada e linear. Conforme AC, a linguagem fala por si, por isso, o eu-lírico é retirado e a poesia pode se autoexplicar por meio de sua estrutura, onde a forma se liga ao conteúdo e ao estilo, a palavra é trabalhada tridimensionalmente, em sua máxima potência, como expressão viva: uma palavra-coisa metalinguística. Segundo Pignatari et ali, "o poeta concreto vê a palavra em si mesma - campo magnético de possibilidades - como um objeto dinâmico, uma célula viva, um organismo completo, com propriedades psicofisicoquímicas tacto antenas circulação coração: viva.” (1975, p.44). Essa ideia de linguagem viva também dialoga com a perspectiva bakhtiniana, que a compreende em uso, no ato enunciativo, como "organismo vivo" (VOLÓCHINOV, 2017).

A composição de AC começou pelo desenho, que ecoa, como estilo estético, em sua poética autoral. Sua obra não endeusa o verbal. Ao contrário. Elabora-o em consonância com elementos visuais e sonoros (fontes, fonemas e tipografia da palavra, por exemplo). Em sua produção, há o trato das três dimensões da linguagem (cores, 
fontes, tamanhos, espaçamentos, simetrias, sons, lexemas, disposição espacial etc) simultaneamente, como processo composicional integrado e unitário do poema. A poética concreta evita o tédio (tal qual propõe a significação do termo em provençal noigandres ${ }^{2}$, que intitula a revista e o grupo fundador do movimento), ao romper com o padrão linguístico (especialmente, a linearidade) e ao se tornar interdisciplinar (pelo diálogo com a música, a arquitetura, as artes plásticas, o design etc).

Poetamenos (1953) se configura como um projeto novo de design, com outra disposição espacial da página e do poema, a quebra do verso e da estrofe, cores marcando possibilidades vocais/sonoras e abandono da sintaxe, como em "Lygia Fingers" (Figura 1), que integra a obra.

Esse poema, de inspiração mallarmeana, exemplifica a disposição poética, com a inovação da introdução de cores quentes e frias marcando morfemas em versos distintos, nem sempre da mesma língua, mas de códigos variados, compondo signos e vozes plurais. Nessa obra ideogramática, as palavras se descolam da página e adentram umas às outras.

Com influência da música serial, palavras marcadas por cores diferentes expressam timbres vocais (poema gravado em áudio ${ }^{3}$ ). Como aponta Zhou (2018), no prefácio de Poetamenos, AC também se inspira em Rimbaud ao colorir as letras, de acordo com a técnica Klangfarbenmelodie (melodia de timbres), de Anton Webern, primeiramente criado por Schoenberg para tratar de uma sucessão de tons e cores relacionadas entre si, de forma parecida com o relacionamento de tons em melodia, dado que "[...] incorpora estruturalmente os timbres de cada instrumento em uma composição musical, criando uma textura disjuntiva e ainda variada na melodia, com possíveis correspondências rítmicas adicionais" (ZHOU, 2018, p.12) - técnica musical de referência ao pontilhismo, método de pintura e coloração.

\footnotetext{
${ }^{2}$ Segundo explicam Pignatari et ali (1975), há certo mistério semântico sobre o lexema provençal noigandres, que se decompõe em enoi (tédio) e gandres (proteger) e, pela etimologia, remete à proteção contra o tédio, seu antídoto.

${ }^{3}$ Disponível em: https://youtu.be/Zy74PDQC7zc. Acesso em 06 set 2021.
} 
Figura 1 - Poema “Lygia Fingers” (1953)

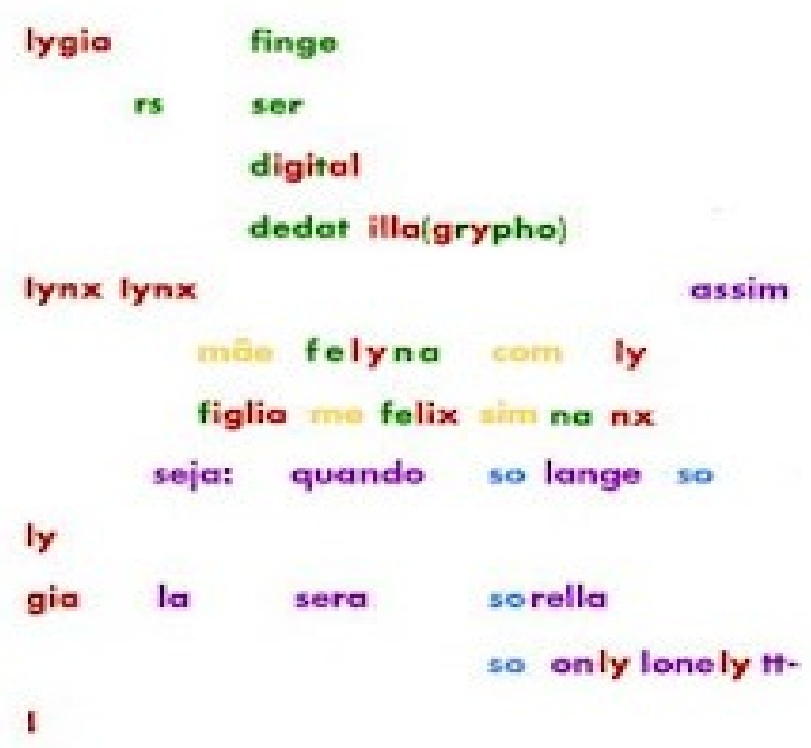

Fonte: Site oficial de Augusto de Campos ${ }^{4}$

O fazer augustiano explora o timbre de/em cada palavra, pela presença gráfica e fonética: a representação visual das cores das letras, com a tipografia utilizada, pode distinguir timbres no que tange à diferenciação cromática de leitura polifônica.

Esse trabalho sincrético exemplifica como a verbivocovisualidade compõe a unidade enunciativa integral da obra, como ela constitui a poética de $\mathrm{AC}$, do concretismo e da proposta bakhtiniana de linguagem (inclusive, ao que tange à noção de polifonia BAKHTIN, 2015).

Nesse diálogo formador do trabalho augustiano, a pausa (constitutiva da música) é parte da estrutura poética, o que está marcado no enunciado da Figura 1 pelos espaçamentos entre as palavras e a disposição do poema na página: os espaços brancos marcam o silêncio e substituem a pontuação, dispensável, dada a elaboração prosódica indicada pelas cores, que marcam a entonação. A estética concreta é mantida no diálogo entre forma, conteúdo verbal, vocal, visual e estilo, autoral e genérico, com sua construção planejada. Segundo Campos,

A construção matemática do poema e a posição de cada palavra, com suas diferentes cores, nada tem de arbitrária. Não é apenas focada na expressão de um apelo visual, mas demonstra em si uma profunda relação entre a

\footnotetext{
${ }^{4}$ Disponível em: http://www.augustodecampos.com.br/poemas.htm. Acesso em 05 set 2021.
} 
visualidade e o conteúdo. A discrepância entre forma e conteúdo, que estamos acostumados a observar numa concepção poética mais canônica, não tem espaço no concretismo, pois a profunda intimidade entre eles transforma o poema em uma unidade icônica e verbivocovisual. Podemos analisá-lo em suas formas, espaços em branco, em sua semântica não tradicional, em sua não linearidade. (2019, p. 109)

A máxima potência tridimensional da poesia concreta marca uma estética política, pois, mais que renovar, transforma a concepção de linguagem como elemento humano e sociocultural. Os poemas de AC se apresentam como quadros, músicas, móbiles, clipes, animações, instalações etc. Suas obras expressam a integração entre forma, conteúdo e estilo, elaborados como unidade de linguagem, entendida e tomada como verbivocovisual.

Em "Código" (Figura 2), as letras giram sobre um eixo vertical, em volta de si mesmas e entre si, formando a palavra-título "Código", numa função metalinguística que descentraliza a noção de língua(gem), num jogo que depende do sujeito e (re)constrói a ideia de código:

Figura 2 - Poema "Código" (1973)

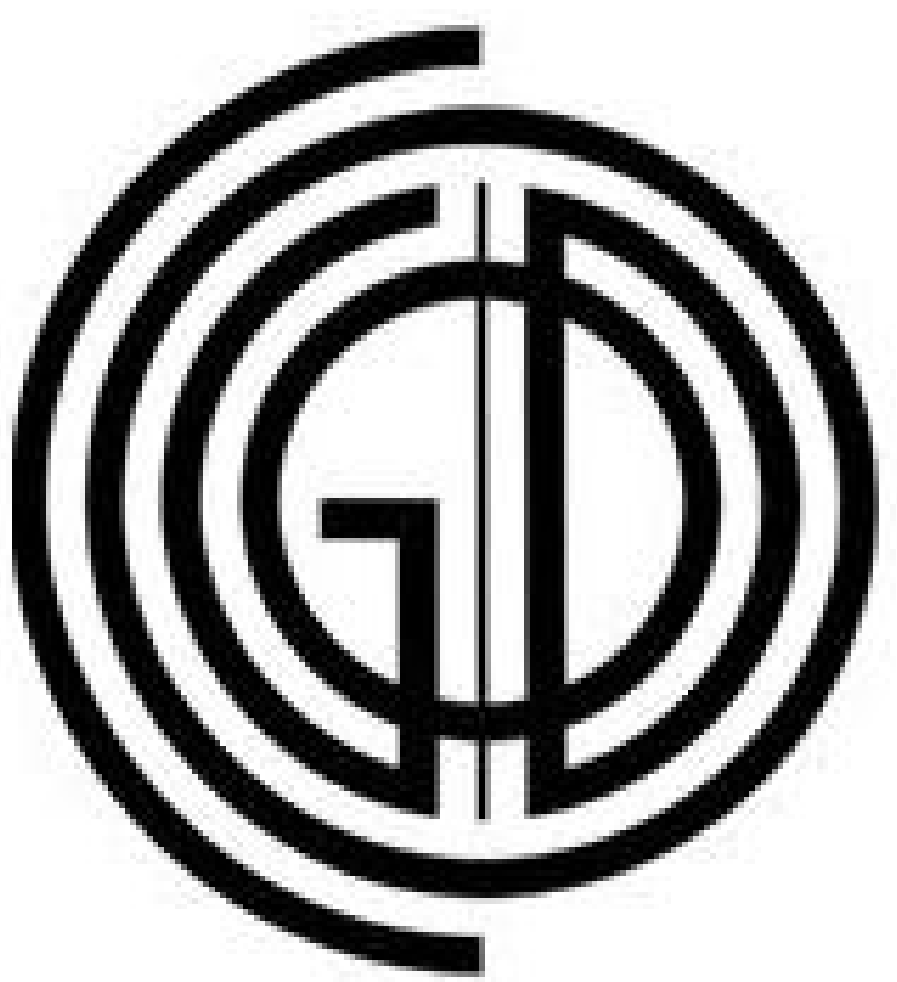

Fonte: Site oficial de Augusto de Campos ${ }^{5}$

\footnotetext{
${ }^{5}$ Disponível em: http://www.augustodecampos.com.br/poemas.htm. Acesso em 05 set 2021.
} 
O poema-objeto "Código" integra o projeto Caixa Preta (1975), de AC e Júlio Plaza. A exposição denominada Rever, realizada pelo Sesc, em 2016, teve uma montagem aumentada do poema, numa estrutural de metal, em que o leitor interage com o poema e constrói seu sentido. Em papel, as letras em tamanhos decrescentes criam efeito tridimensional e labiríntica.

A tipografia enlaça o visual ao verbal. O movimento de formação do signo "Código" (de fora para dentro, em movimento da esquerda para a direita e da direita para a esquerda) materializa a dimensão vocal/sonora do verbal: os sons abertos $(/ \mathrm{O} /$, por exemplo) são ascendentes e vão se fechando (/o/) até o final descendente da palavra proparoxítona (com a primeira sílaba tônica - mais forte e aberta; e a última, átona, a mais fechada e baixa do termo).

Como todo labirinto, há um caminho a ser percorrido pelo leitor para a composição do poema. O movimento de leitura revela o posicionamento do autor-criador e a integração das três dimensões da linguagem pelos elementos (que parecem "pequenos detalhes") do poema-objeto instaura a metalinguagem. O leitor adentra o código poético, das extremidades ao centro, da proximidade à profundidade (em perspectiva), em tom cromático negro (misterioso, desconhecido) e em movimento de transe-trânsito icônico.

Ler o poema-objeto de AC significa adentrar em seu universo, que se con-funde com o concretista, o de uma concepção de língua(gem) e de poesia. "Código" instaura o convite interativo à metalinguagem sobre si, sem despregá-lo do mundo e do homem.

A verbivocovisualidade é a ponte para pensarmos a linguagem do Círculo, presente na poética concreta, inter-ativa, que precisa do sujeito-outro para engendrar a compreensão em ato.

\section{Verbivocovisualidade interativa: os clip-poemas de Augusto de Campos}

Os clip-poemas acontecem na interação. O diálogo, ponto nevrálgico bakhtiniano, não se refere apenas à relação sujeito-enunciado ou a cada sujeito, mas também entre línguas e dimensões de linguagem. O diálogo é responsável pela construção de sentidos. No caso de AC, o leitor, numa relação entre sujeitos (autor-criador do poema e leitores) e vozes sociais, decodifica a obra, sendo co-responsável pela construção de sentidos.

Revista da Anpoll, Florianópolis, v. 52, n. 3, p. 55-75, set.-dez., 2021 | 65 
$\mathrm{Na}$ obra estética de AC, a linguagem verbivocovisual desafia o leitor, chamado a participar ativamente dos poemas. Esse traço estilístico de sua poética transpassa toda a sua estética, desde a série Poetamenos (1953) até os clip-poemas do livro Não poemas (2003).

Ao mesmo tempo em que são abertos, os poemas concretos possuem caminhos fechados, com uma ordem e dada lógica. Codificado, o poema se abre no jogo de leitura, com seu enigma finalizado na interação. Uma ilustração dessa característica estilística de AC é "Criptocardiograma” (2003) (Figura 3):

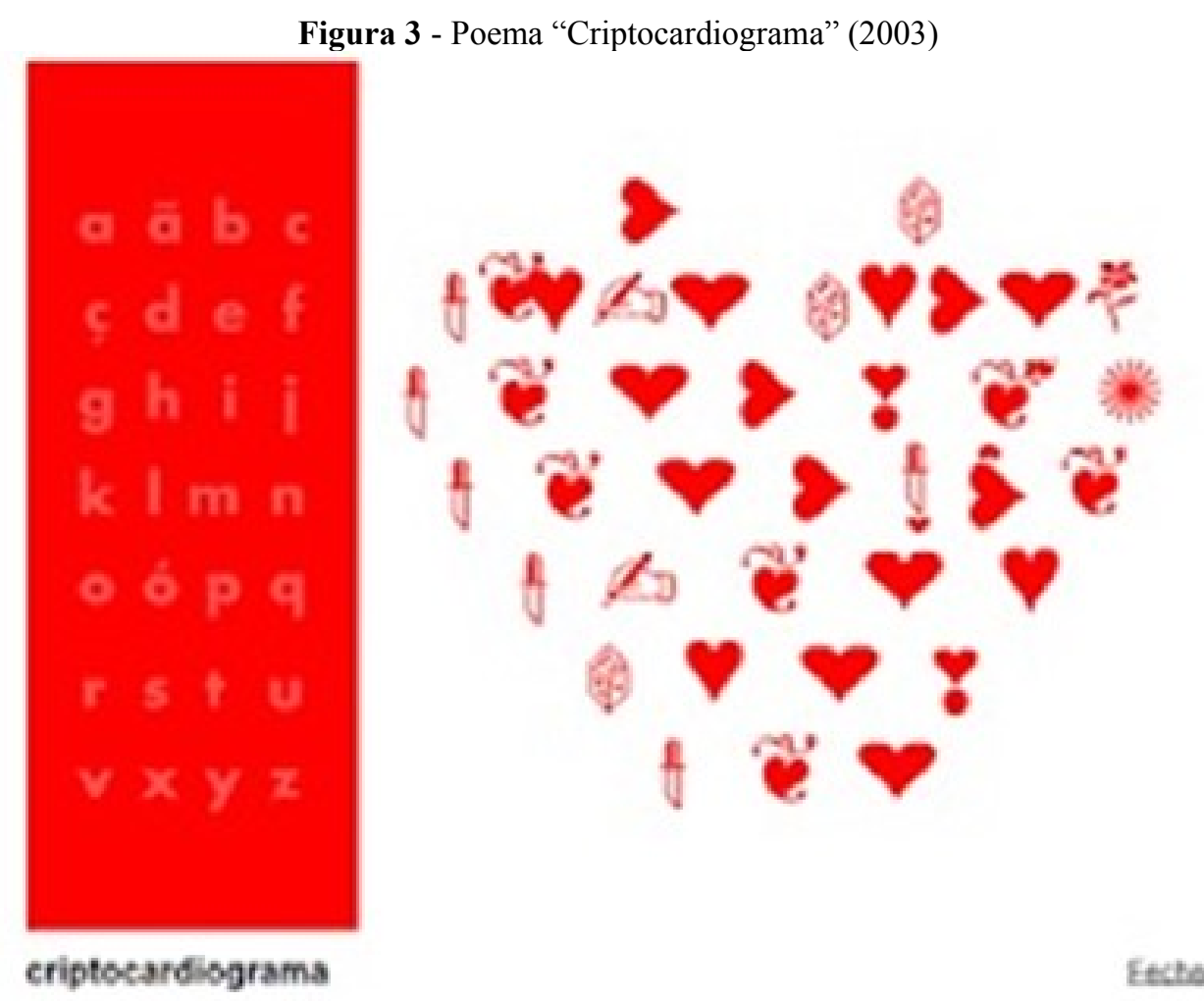

Fonte: Site oficial de Augusto de Campos ${ }^{6}$

Composto, como sugere o título, num jogo de composição morfológica e semântica, como cripto (do grego, kryptós, “escondido") grafia (gráphein, "escrita”), o poema, já no título, insinua uma chave de leitura, que também é uma chave composicional de escritura: o criptograma, como unidade da criptografia, usada para "decifrar" um enigma (no caso, composto por grafemas, fonemas, lexemas e símbolos gráficos).

\footnotetext{
${ }^{6}$ Disponível em: http://www.augustodecampos.com.br/clippoemas.htm. Acesso em 21 set 2021.
} 
O morfema -cardio-, central no título, em interação com a imagem global do poema (em forma de coração e com símbolos que também se referem a esse lexema), sugere o signo ideológico que se forma pela leitura decodificada: coração. Não um coração qualquer, mas o órgão pulsante, prosodicamente entoado quando totalmente decifrado, por diversas vozes que pronunciam, em várias línguas, o termo "coração", quando demandado pelo leitor, ao passar o mouse sobre os signos formados, da mesma forma que, ao descobrir a correspondência imagem simbólica e grafema/fonema, o poema pulsa (com som de pulsação do coração e um breve "pisca" visual que remete ao batimento cardíaco). Não se trata apenas do coração como metáfora do amor, mas do coração-coisa/objeto literal, o órgão-cardio.

O poema "Criptocardiograma" adquire sentido no acontecimento de leitura, pelo ato interativo de decodificação do outro/leitor que pode escolher por onde começar, mas precisa estabelecer uma lógica de leitura pré-determinada no poema pelo autor-criador: via criptologia, que estuda os conhecimentos (matemáticos, computacionais, linguísticos etc) e técnicas (verbais, visuais, vocais/sonoras) necessários à criptoanálise (solução de criptogramas) e à criptografia (escrita codificada). Com essa obra, uma outra concepção de poesia é expressa: pelas três dimensões da linguagem em movimento no suporte digital, a poesia acontece, no ato interventivo de leitura, em que o outro/leitor descobre/decifra/decodifica os sentidos criptocardiogramados do/no poema. Nas palavras de Dias e Tibúrcio,

O poema "Criptocardiograma" não acontece caso o leitor não se sinta desafiado o bastante para arrastar na tela cada letra, numa tentativa de decifrar a estrutura e o(s) significado(s) do poema. Mais que interpretação, o leitor torna-se um interventor e contribui para a própria construção do poema, tornando-se uma espécie de coautor, graças às ferramentas digitais disponibilizadas. (2017, p. 262)

Os ícones imagéticos criptografados são formados por trevos, corações, dados e adagas que remetem aos quatro (4) naipes de um baralho. Esses elementos convidam o leitor a jogar com o poema experimental, pois o sentido da obra depende da ação multiletrada interativa.

Os elementos gráficos junto com o coração formado no todo do poema, têm a função de chamar a atenção do leitor para o clip-poema vermelho-sangue, aberto, pulsante, vivo.

Revista da Anpoll, Florianópolis, v. 52, n. 3, p. 55-75, set.-dez., 2021 | 67 
Segundo Heller (2013, p. 103), o vermelho é a cor das paixões (boas ou más):

Por detrás do simbolismo está a experiência: o sangue se altera, sobe à cabeça e o rosto fica vermelho, de constrangimento ou por paixão, ou por ambas as coisas simultaneamente. Enrubescemos de vergonha, de irritação ou por excitação. Quando se perde o controle sobre a razão, "vê-se tudo vermelho". Pintamos os corações de vermelho, pois os enamorados acreditam que todo o seu sangue aflui ao coração.

Assim, se, ao mesmo tempo, o coração poético se refere ao órgão em si (denotativo), ele também remete às paixões (conotativo). $\mathrm{O}$ símbolo do coração com o dado em sua ponta inicial marca o acaso no assunto amoroso: "Sorte no jogo, azar no amor". Jogo amoroso não planejado ou controlado, ao contrário do jogo poético arquitetado em "Criptocardiograma”. Nesse sentido, o jogo poético, metalinguístico, não coincide, pelo contrário, ao acaso amoroso, ainda que ambos dependam do outro e o convidem a se consumar, suas construções são de ordens/lógicas distintas, como afirma Mallarmé em Un coup de dés (1897).

Os naipes do jogo amoroso, embaralhados, como na relação afetivo-amorosa, podem parecer aleatórios e confusos, mas têm, cada qual, sua função e seu sentido planejado numa codificação ordenada, desde a sua disposição espacial até as letras/gramas. Conforme Mata,

[...] os dados são o azar (ou o amor); a flor pode ser um presente, a vida; a mão que escreve talvez a ideia de comunicação, as cartas trocadas; o punhal está no lugar da agressão, traição ou perigo; e os dois tipos de coração podem ser o encontro, a companhia, o outro. As posições de cada ícone também entram nas possibilidades: um coração reclinado, um que tem um pequeno círculo debaixo de seu vértice, outro que exibe um coraçãozinho inclinado em cima, outro coração pequeno que parece oprimido pela ponta de um dos punhais. Todas as figuras estão em vermelho, que é a cor do sangue, da paixão. $O$ asterisco pode ser um sol brilhante, mas se é um asterisco indica uma aclaração não resolvida, algo obscuro, uma zona notável, mas indecifrável, de um coração. Se vamos ao sentido literal do poema, somamos o escondido de "cripto", o coração de "cardio", a letra de "grama", e a técnica médica do "cardiograma" (2018, p. 29-30).

A tipografia, impressão dos tipos (letras e fontes) gráficos, é um processo de composição presente na poética de AC, como afirma Santos (2020). O uso da fonte "Futura" é comum devido à influência dos movimentos da nova tipografia de Tschichold e do funcionalismo bauhausiano, como aparece em "Lygia Fingers" (1953) (Figura 1). “A tipografia na poesia concreta é um instrumento essencial para definir a espacialização 
visual da escrita, a expressão da linguagem, pelo espírito, ritmo, entoação e silêncio, que se transformará na expressão sonora do poema" (SANTOS, 2020, p. 521). Assim, o visual, o verbal e o vocal/sonoro se ancoram e explicitam, em movimento dialéticodialógico tridimensional, que liberta a poesia para outras formas de construção de sentido.

No poema em análise, a visualidade é criptografada, pois as letras aparecem quando o leitor-autor-jogador atua no poema e decodifica cada símbolo-letra. Há uma intersecção entre tipografia e critptografia em "Criptocardiograma", uma vez que cada letra-grafema-fonema é representada por um símbolo. Assim, uma criptotipografia representa cada unidade mínima de linguagem que arquiteta a constituição global do poema. No caso da Figura 4, o /o/ é representado por um dos cripto-tipos de coração:

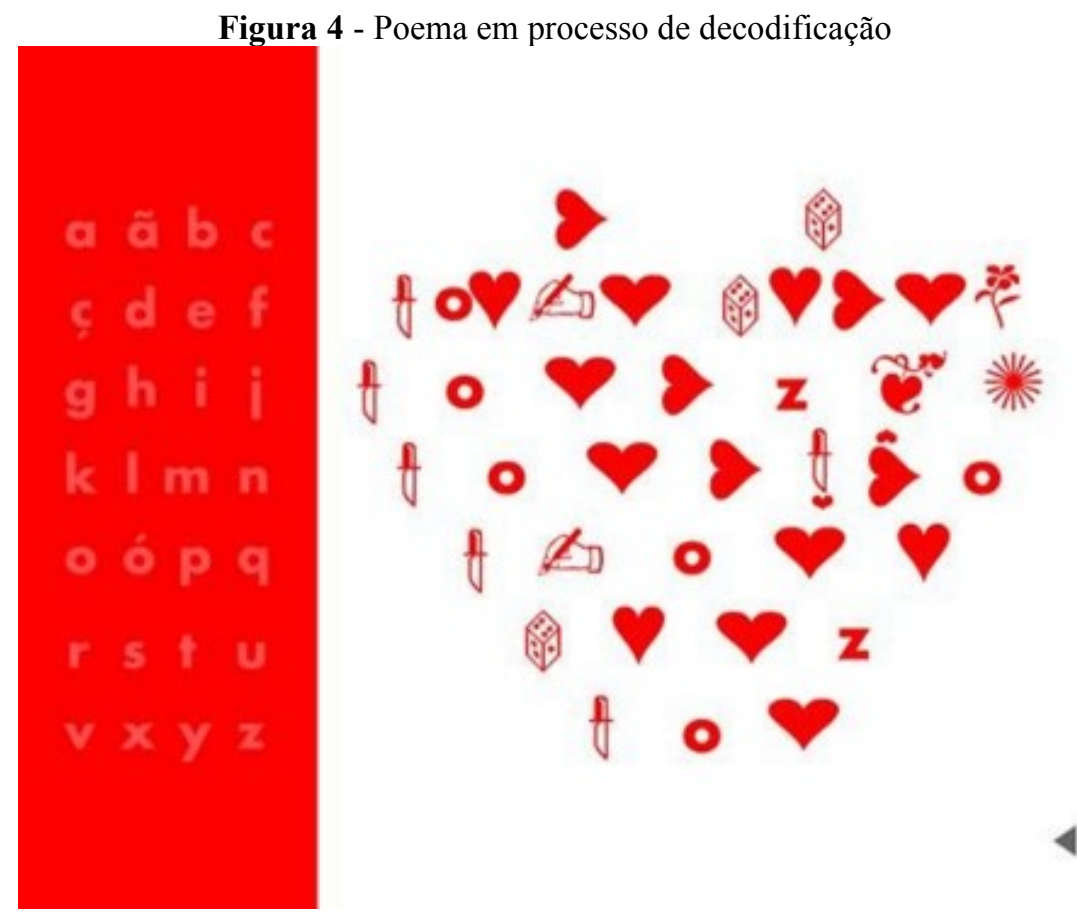

Fonte: ARANHA e BORBOREMA, 2006, p. 59

Cada movimento de leitura-ação acertado é suportado por um som que confirma e instiga uma nova ação de leitura em cadeia - o que remete à noção de enunciado bakhtiniana, que considera o elo na corrente discursiva e a singularidade de cada ato discursivo. Esse som recebe uma entonação vocal específica, que une significado e significante, compondo a unidade sígnica enunciativa do poema. Sua forma, expressão material em som, acontece num ato específico arquitetado: com o acerto é que som e sentido se articulam, pela indução que engata a continuação da composição do 
jogo/poema. Dentro desse código, forma-se um amplo coração ao lado de uma chave lexical que deve ser, letra por letra, arrastada ao símbolo correspondente para transcodificar a obra, enquanto sobram letras que indicam outras possibilidades de criação, ainda que o poema não possa ser alterado. Ao decodificar, a verbalidade aparece, formando lexemas em diferentes línguas, todas com o significado de "coração" (Figura 5):
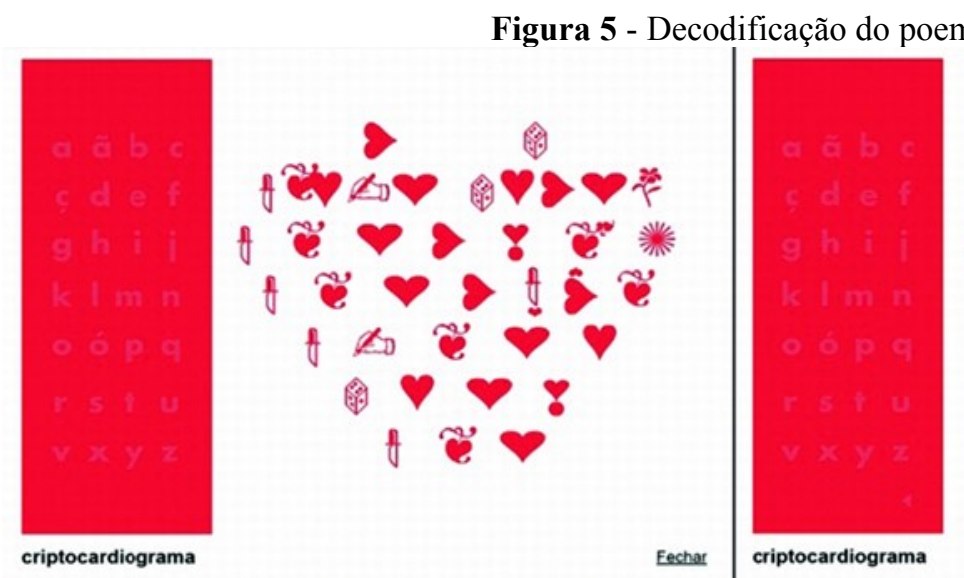

Figura 5 - Decodificação do poema

Fonte: CARVALHO, 2007, p. 81

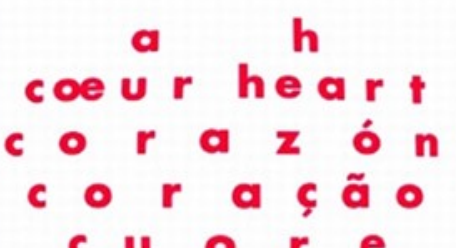

c u $\quad r$ e

he $r z$

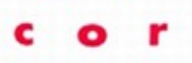

A versão impressa do poema (Figura 6) tem uma incompletude que suscita o clippoema, existente no CD-Room que acompanha o livro impresso, como parte integrante de sua unidade, pois apenas na integração que sai do papel e vai para o computador é que se firma, num jogo lúdico centrado no tema da organicidade amorosa, confirmada pelas imagens e pela vocalidade, que o criptopoema passa a ter sentido pleno. A versão impressa, por impossibilitar a interação, cristaliza o enigma não solucionado. A verbivocovisualidade é aqui destacada também pela diversidade de códigos e suportes. 


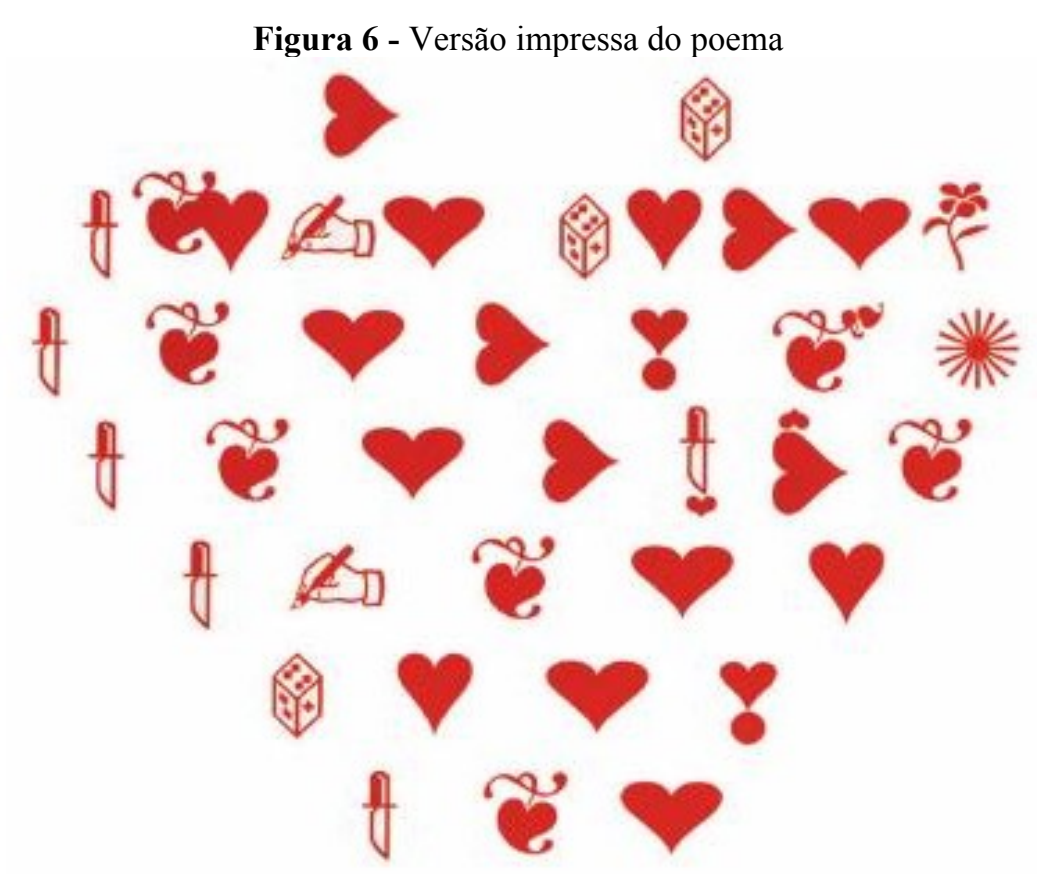

Fonte: CARVALHO, 2007, p. 81

O leitor integra o projeto estético concreto ao ser chamado a adentrar o universo poético, uma vez que se apercebe numa espécie de salão de jogos, onde é convidado a atuar-brincar/jogar para desvendar/decodificar os sentidos discursivos do coração em jogo.

A interação dialético-dialógica caracteriza o estilo autoral criador de $\mathrm{AC}$, pois constitui a sua arquitetônica poética, que iconiza o projeto verbivocovisual concreto e este, casa-se com a perspectiva tridimensional de linguagem bakhtiniana.

\section{Considerações finais}

A verbivocovisualidade como concepção estética concreta e de AC constitui não apenas um projeto poético revolucionário e inovador, mas também uma concepção integradora de linguagem. Nesse sentido, nossa hipótese é confirmada, uma vez que a tridimensionalidade verbivocovisual constitui a unidade integral da linguagem, trabalhada em máxima potência, num exercício de elo com um tempo longínquo, como citamos nas palavras de AA, em que as dimensões da linguagem e os próprios elementos da língua não se encontravam separados. Ao contrário, compunham sua totalidade ou, nas 
palavras dos estudiosos russos, como também citamos, "a potencial linguagem das linguagens única" (BAKHTIN, 2011, p. 311).

Ao dialogar a noção de verbivocovisualidade concreta à concepção de linguagem bakhtiniana, estabelecemos ligação entre correntes artísticas e filosóficas, temposespaços e visões de mundo que vão, desde as inspirações e os estudos empreendidos para formarem uma ideia de linguagem, até o ato de criação e análise estética, pois mesmo que cada grupo tenha suas características e propósitos específicos, respondem um ao outro.

Este artigo refletiu, a partir dos poemas de AC analisados, um diálogo responsivo entre a proposta tridimensional de linguagem bakhtiniana e a noção verbivocovisual estética concretista. Pelo método dialético-dialógico, foi possível relacionar os grupos ao que se refere à concepção de linguagem integral. O nosso objetivo foi alcançado com as análises que demonstraram como a arquitetônica concreta de $\mathrm{AC}$ sincretiza as dimensões da linguagem sem hierarquizá-las, ao contrário, amalgamando-as de forma codificada explícita - no caso, a partir dos elementos composicionais estilísticos autorais do autorcriador.

A tese defendida de que a linguagem geral, como entendida pelo Círculo russo, não é impossível, mas sim uma proposta real, engendrada de modo propositivo por Joyce (com relação à composição de seus romances) e expresso de forma máxima pela poesia concreta, é a contribuição desta reflexão. Essa relação é relevante para os estudos bakhtinianos porque demonstra a produtividade de sua filosofia da linguagem proposta na abordagem analítica de enunciados contemporâneos, especialmente, os explicitamente marcados como multimodais.

\section{Contribuição}

Luciane de Paula: Conceitualização, Curadoria de Dados, Investigação, Supervisão, Escrita - rascunho original, Escrita - análise e edição; Rafaela dos Santos Batista: Curadoria de Dados, Investigação, Escrita - rascunho original, Escrita - análise e edição.

\section{Referências}

ANTUNES, A. Sobre a origem da poesia. In: MOREAU, G. (Org.). 12 Poemas para dançarmos. São Paulo: SESC, 2000. 
ARANHA, S. D. de G.; BORBOREMA, O. R. A interatividade na poesia digital: palavra, imagem e som em movimento. Texto Livre: Linguagem e Tecnologia, Belo Horizonte, v. 9, n. 2, p. 46-63, 2016. Disponível em: https://periodicos.ufmg.br/index.php/textolivre/article/view/16726. Acesso em: 7 set 2021.

BAKHTIN, M. Para uma filosofia do ato responsável. Tradução de Valdemir Miotello \& Carlos Alberto Faraco. São Carlos: Pedro e João, 2010.

BAKHTIN. M. Estética da Criação Verbal. Tradução de Maria Emsantina Galvão G. Pereira. São Paulo: Martins Fontes, 2011.

BAKHTIN, M. Problemas da Poética de Dostoiésvki. $5^{\text {a }}$ ed. Tradução de Paulo Bezerra. Rio de Janeiro: Forense Universitária, 2015.

BAKHTIN, M. Os gêneros do discurso. Tradução de Paulo Bezerra. São Paulo: 34, 2016.

CAMPOS, A. de. Não poemas. São Paulo: Perspectiva, 2003.

CAMPOS, A. de. Poetamenos. São Paulo: Edições Invenção, 1973.

CAMPOS, A. de; PLAZA, J. Código. Caixa Preta. São Paulo: Invenção, 1975.

CAMPOS, R. B. Entre vivas e vaias: a visualidade concreta de Augusto de Campos. Tese (Doutorado em Literatura), Universidade de Brasília, Brasília, 2019, 153f.

CARVAlho, A. Ap. F. de. Poesia concreta e mídia digital: o caso Augusto de Campos. Dissertação (Mestrado em Comunicação), Pontifícia Universidade Católica de São Paulo. São Paulo, 2007, $113 f$.

DIAS, A. V. M.; TIBÚRCIO, F. Para além da palavra: multissemiose e hibridismo na urdidura do ciberpoema. FronteiraZ, n. 19, p. 253-271, 2017. Disponível em: https://revistas.pucsp.br/index.php/fronteiraz/article/view/28359. Acesso em 18 set 2021.

HELLER, E. A psicologia das cores: como as cores afetam a emoção e a razão. São Paulo: Gustavo Gili, 2013.

JAKUBINSKIJ L. Sobre a fala dialogal. São Paulo: Parábola, 2015.

MALLARMÉ, S. et al. Un coup de dés. Baudouin, 1979.

MATA, R. Augusto de Campos: Outro. CIRCULADÔ Revista de Estética e Literatura do Centro de Referência Haroldo de Campos - Casa das Rosas. Disponível em: http://www.casadasrosas.org.br/crhc/arquivos/cr_circulado_edicao 8.pdf. Acesso em: 7 set. 2021. 
MEDVIÉDEV, P. O Método Formal nos Estudos Literários. Tradução de Sheila Camargo Grillo e Ekaterina Vólkova Américo. São Paulo: Contexto, 2012.

PAULA, L. de. O enunciado verbivocovisual de animação: a valoração do "amor verdadeiro" Disney - uma análise de Frozen. In: FERNANDES Jr, A.; STAFUZZA, G. B. (Orgs). Discursividades contemporâneas: política, corpo, diálogo. Campinas (SP): Mercado de Letras, 2017, p. 287-314.

PAULA, L. de; LUCIANO, J. A. R. A filosofia da linguagem bakhtiniana e sua tridimensionalidade verbivocovisual. Estudos Linguísticos. São Paulo, v. 49, n. 2 2020a, p. 706-722. DOI: https://doi.org/10.21165/el.v49i2.2691. Acesso em: 18 set 2021.

PAULA, L. de; LUCIANO, J. A. R. A tridimensionalidade verbivocovisual da linguagem bakhtiniana. Linha D’Água, v. 33, n. 3, 2020b, p. 105-134. DOI: https://doi.org/10.11606/issn.2236-4242.v33i3p105-134. Acesso em: 18 set 2021.

PAULA, L. de; LUCIANO, J. A. R. Filosofia da linguagem bakhtiniana: concepção verbivocovisual. Revista Diálogos - RevDia, v. 8, n. 3, 2020c, p. 132-151. Disponível em: https://periodicoscientificos.ufmt.br/ojs/index.php/revdia/article/view/10039. Acesso em: 18 set 2021.

PAULA, L. de; LUCIANO, J. A. R. Dialogismo verbivocovisual: uma proposta bakhtiniana. Polifonia, v. 27 n. 49, 2020, p. 15-46. Disponível em:

https://periodicoscientificos.ufmt.br/ojs/index.php/polifonia/article/view/11366. Acesso em: 18 set 2021.

PAULA, L. de; LUCIANO, J. A. R. The Verbivocovisual Architectonic of the Stage La Conversione Di Un Cavallo. Global Journal of Human Social Sciences-A - GJHSSA, v. 21, n. 13, 2021, p. 01-13. Disponível em:

https://globaljournals.org/GJHSS Volume21/EJournal_GJHSS (A) Vol_21_Issue 13.pdf. Acesso em: 18 set 2021.

PAULA, L. de; SERNI, N. M. A vida na arte: a verbivocovisualidade do gênero filme musical. Raído, v. 11, n. 25, 2017 p. 178-201. DOI:

https://doi.org/10.30612/raido.v11i25.6507. Acesso em: 18 set 2021.

PIGNATARI, D.; CAMPOS, A. de; CAMPOS, H. de. Teoria da poesia concreta: textos críticos e manifestos (1950-1960). São Paulo: Livraria Duas Cidades, 1975.

SANTOS, T. Design e tipografia como elementos da expressividade da poesia de Augusto de Campos. ARS, v. 18, n. 40, 2020, p. 508-584. Disponível em: https://doi.org/10.11606/issn.2178-0447.ars.2020.160035. Acesso em: 18 set 2021.

VOLOCHÍNOV, V. A construção da enunciação e outros ensaios. Tradução de João Wanderley Geraldi. São Carlos: Pedro \& João, 2013. 
VOLOCHÍNOV, V. Marxismo e filosofia da linguagem. Problemas fundamentais do método sociológico na ciência da linguagem. Tradução de Sheila Grillo e Ekaterina Vólkova Américo. São Paulo: 34, 2017.

VOLÓCHINOV, V. A palavra na vida e a palavra na poesia. Tradução de Sheila Grillo e Ekaterina Vólkova Américo. São Paulo: Editora 34, 2019.

ZHOU, I. A Palavra-Valise de Augusto de Campos. CIRCULADÔ Revista de Estética e Literatura do Centro de Referência Haroldo de Campos - Casa das Rosas, São Paulo, 2018. Disponível em:

http://www.casadasrosas.org.br/crhc/arquivos/cr_circulado_edicao_8.pdf. Acesso em: 7 set 2021. 